\title{
ResidenCy AdMinistration
}

\section{Academic Career Selection in American Emergency Medicine Residents}

\author{
John Burkhardt, MD, MA, Terry Kowalenko, MD, and William Meurer, MD, MS
}

\begin{abstract}
Background: The future of academic emergency medicine (EM) is based on the continued successful recruitment and cultivation of new faculty from EM residents. Little data exist as to the current rate of residents initially choosing an academic career path or which residency programs are best situated to result in new faculty.
\end{abstract}

Objectives: Our study was designed to initially describe the current career demographics of graduating residents and then through statistical analysis investigate likely programmatic factors that affect academic career selection.

Methods: Data were collected via an online survey sent to EM residency program directors. Responders were asked to describe their graduates and their program characteristics over the past 5 years. A total of 103 survey responses, with complete data from 65 (76 responses contained enough data for national career selection rates), were received. Relevant covariates were tested for association with academic career entry using t-tests or analysis of variance. An adjusted multivariable linear regression analysis model was then fitted.

Results: Survey responses indicated that $26.1 \%$ of residents chose an academic career (community $57.1 \%$, fellowship $13.5 \%$, military/Veteran's Administration [VA] 2.6\%, other $0.6 \%$ ) with an approximately normal distribution. There were no significant differences found between programs when presence of mentorship programs, career track programs, or city size were analyzed. Multivariable linear regression analysis demonstrated significantly greater academic career choice among programs located in the Northeast/Mid-Atlantic and the Midwest, larger programs ( $>12$ residents/year), and programs with increased resident academic productivity (presentations given, non-peer-reviewed publications), but did not demonstrate a difference between 3- and 4-year programs. Overall, the model fitted using the above variables accounted for approximately 30\% of the variation seen between programs (adjusted $R^{2}=0.295$ ).

Conclusions: Our data indicate that program region, size, and research productivity were best associated with academic career selection. Program length was not found to be significantly associated with academic career selection by residents, in contrast to previous studies. While many of these factors are not changeable, academic productivity can be cultivated by decision-makers wishing to increase their residents' academic career selection as opposed to changing program length to extend training for an additional year. It is our belief that our model provides a good description of programmatic factors affecting career choice. Additional research is necessary to further validate these findings, as well to provide important context to their general applicability for policy-makers and program directors.

ACADEMIC EMERGENCY MEDICINE 2011; 18:S48-S53 @ 2011 by the Society for Academic Emergency Medicine

$\mathrm{T}$ he future of academic emergency medicine (EM) is based on the continued successful recruitment and cultivation of new faculty in each generation of residency-trained emergency physicians (EPs). This need comes in the setting of a history of continuing projections of deficits of EPs for the foreseeable future. ${ }^{1-3}$ While all new EM residents have the potential to enter an academic career, and thus constitute a large

From the Department of Emergency Medicine (JB, TK, WM), the Department of Medical Education (JB, TK), and the Department of Neurology (WM), University of Michigan, Ann Arbor, MI.

Received April 22, 2011; revision received June 24, 2011; accepted June 27, 2011.

Presented at the Council of Emergency Medicine Residency Directors (CORD) Academic Assembly 2011.

The authors have no relevant financial information or potential conflicts of interest to disclose.

Supervising Editor: Nicole M. DeIorio, MD.

Address for correspondence and reprints: John Burkhardt, MD, MA; e-mail: jburkhar@umich.edu. 
population of potential faculty members, the majority make other choices, including community practice or military service. ${ }^{4,5}$ Previous research in career selection has evaluated specialty choice in medical students with regard to $\mathrm{EM}^{6}$ first practice location in respect to geographical area ${ }^{7,8}$ and has begun to investigate what factors are associated with academic career selection following graduation from residency. ${ }^{9-11}$ Little current data exist, however, as to how frequently residents initially choose an academic career path. More importantly, the majority of the research has focused on individual resident characteristics, with less time devoted to programmatic variables associated with increased development of junior faculty. ${ }^{9}$ Studies concentrating on program evaluation have previously focused on the differences between program type, mainly 3-year versus 4-year programs, where in this study we attempted to expand this to additional factors distinguishing EM residencies. ${ }^{4,5}$

The purpose of this study was to describe the programmatic factors that appear to be associated with residency programs most likely to generate new academic EM faculty. We hypothesized that there would be a significant difference in academic career selection based on program type as demonstrated in previous studies; however, we also believed that there would be demonstrable differences between programs based on cultural programmatic factors such as regional location and research productivity. In this way the study is designed to update the available data on national trends in academic career selection, reexamine previous conclusions found in the literature in the current setting, and assess new programmatic factors associated with higher academic-bound graduates. We feel that our additional variables provide novel information about programmatic factors not previously described or evaluated in the literature and that the linear regression model generated provides a new and unique insight into this issue. With regard to academic career selection rates, we expect the previously described rate to either stay the same or potentially be lower than previously reported. We created this hypothesis after weighing the competing economic incentives for an academic career in an era of increasing economic uncertainty and decreased wages across multiple professions. Recent research in other fields such as radiology has found a decline in academic career selection due to similar issues. $^{12}$ The ultimate goal of this research is to begin laying the groundwork for an ongoing effort to provide critical information for educational policy-makers and program directors with respect to program and academic faculty development.

\section{METHODS}

\section{Study Design and Population}

This was a cross-sectional study that used an online survey instrument. The target cohort for the distribution of the survey was EM residency program directors in American allopathic residency programs in 2010. All active programs with contact information on the Council of Emergency Medicine Residency Directors (CORD) database were included in the distribution of the survey; the home program of the authors was excluded to avoid possible reporting biased. Institutional review board exemption was received prior to initiation of the survey.

\section{Survey Content and Administration}

Emergency medicine residency program directors were solicited via e-mail for participation in an online survey created by the authors explicitly for this study. Unique program identifiers were provided for each program director to deidentify survey responses while allowing for accurate recording of those programs that completed the survey. Following initial data collection, repeat e-mails were distributed to maximize survey responses. The survey was administered using surveymonkey.com for online accessibility. E-mails were directed to program directors who had not completed the survey at approximately 30 and 60 days after initial distribution to maximize the survey response rate.

Survey Measures. Survey questions were developed following a literature search of the previous research findings as well as inclusion of new programmatic factors thought likely to contribute to academic career selection. The questions were refined following the initial review of the literature through solicitation of feedback from senior residency leadership at the home program. The online survey consisted of 17 questions that included multiple choice and free-text responses designed to obtain data on programmatic variables including program type, regional location, primary city type, program size, educational programs (presence of mentorship and career track programs), and resident research productivity (peer-reviewed publications, non-peer-reviewed publications, and meeting presentations). Multiple choice answers constituted the variables as described under Results, free-text answers were allowed for input of percentages of residents engaged in activities and entering specific career areas. Programs directors were asked to define their program type as a postgraduate year (PGY) 1-3 program, a PGY 1-4 program, or a PGY 2-4 program. Regional location was defined by program directors into one of five groups (Northeast/Mid-Atlantic, Southeast, Midwest, Southwest, and West). Program directors defined their program size as belonging to one of four groups (6 to 8 graduates per year, 9 to 11 graduates per year, 12 to 15 graduates per year, and 16 or more graduates per year). Additionally within the survey, program directors or their designates were asked to describe their graduates from the past 5 years. This information included general demographics as well as information about the first position taken after completing residency. Academic setting for purposes of this study was defined as including all positions that require regular teaching or supervision of EM residents, full- or part-time appointment at a medical school, or a position with academic research required for promotion. The definition was intentionally designed to provide for the broadest applicability and to attempt to include all EPs who would define themselves as academicians.

\section{Data Analysis}

The outcome variable was the proportion of residents entering academic careers. Initial explanatory variables 
were determined after literature review and included in the survey, based on our a priori beliefs regarding programmatic factors that might influence academic career selection. The variables were initially tested for univariate association with academic career entry using t-tests or analysis of variance, as appropriate. Following completion of these initial steps, an adjusted multivariable linear regression analysis model was then fitted. Covariates were added sequentially, based on our original hypotheses regarding the relationship with the outcome. The covariate for residency length was examined in all models as it was of primary interest, due to the previous work. Statistical analysis was performed using SPSS version 18 (IBM SPSS, Armonk, NY).

\section{RESULTS}

\section{Response Rate}

At the time of survey distribution, 156 allopathic EM residency programs existed. Of that group, 148 programs had contact information available in the CORD database. Our home program was excluded to avoid possible bias in reporting our data. Of the 155 possible programs, 26 programs had not been in existence long enough to have 5 years of graduates. Therefore, 129 programs were able to provide us complete graduate data. Of the available EM residency programs who received surveys, we received 103 responses to our survey, an overall response rate of $70 \%$ (103 of 147). Of those 103 survey responses, 102 responses (99\%) had sufficient information for descriptive program demographics, 76 responses (74\%) contained enough information for determining national academic career selection rates, and 65 responses (63\%) were appropriate for employment in a linear regression model to assess for statistically significant predictive factors (Table 1). Our response rate of programs capable of providing 5 years of graduation data was 59\% (76 of 129) for describing academic career selection rates and $50 \%$ (65 of 129) for complete, in-depth analysis. Programs that provided incomplete data or corrupted data were not included in the analysis, and no other data were excluded. Responders were asked to provide data about all residents graduating in the past 5 years, without exception, generating a presumed inclusion of $100 \%$ of all residents graduates from those programs. Following completion of the survey program, residency programs that did not respond with data were determined by examining assigned blinded program numbers that did not have data entered in the survey results database. Demographic data were provided for the nonresponder column in Table 1 for comparison with participating programs by individual review of each residency program's available information on the Society for Academic Emergency Medicine database and their individual program websites. These data were available for 41 of 44 of the programs who were initially provided surveys but did not respond.

\section{National Demographic Data}

Survey responses indicated a national average proportion of initial academic career choice of $26.1 \%$, with community career choice representing $57.1 \%$,

\begin{tabular}{|c|c|c|}
\hline Characteristic & $\begin{array}{c}\text { Responders, } \\
n(\%)\end{array}$ & $\begin{array}{c}\text { Nonresponders, } \\
n(\%)\end{array}$ \\
\hline Number overall & 103 & 44 \\
\hline Program type & 103 responses & 41 \\
\hline PGY $1-3$ & $74(72)$ & $36(88)$ \\
\hline PGY 1-4 & $27(26)$ & $3(7)$ \\
\hline PGY 2-4 & $2(2)$ & $2(5)$ \\
\hline Program size & 102 responses & 41 \\
\hline 6 to 8 residents & $25(25)$ & $13(32)$ \\
\hline 9 to 11 & $21(21)$ & $9(22)$ \\
\hline 12 to 15 & $36(35)$ & $18(43)$ \\
\hline 16 and above & $10(10)$ & $1(2)$ \\
\hline Regional location & 102 responses & 41 \\
\hline $\begin{array}{l}\text { Northeast/ } \\
\text { Mid-Atlantic }\end{array}$ & $36(35)$ & $15(37)$ \\
\hline Southeast & $22(22)$ & $5(12)$ \\
\hline Midwest & $27(26)$ & $10(24)$ \\
\hline Southwest & $6(6)$ & $6(15)$ \\
\hline West & $10(10)$ & $5(12)$ \\
\hline $\begin{array}{l}\text { Primary site } \\
\text { environment }\end{array}$ & 102 responses & \\
\hline $\begin{array}{l}\text { Large, urban city (pop. } \\
500,000 \text { or greater) }\end{array}$ & $60(59)$ & \\
\hline $\begin{array}{l}\text { Medium-sized } \\
\text { city (pop. } \\
100,000-500,000 \text { ) }\end{array}$ & $34(33)$ & \\
\hline $\begin{array}{l}\text { Small-sized city (pop. } \\
50,000-100,000)\end{array}$ & $6(6)$ & \\
\hline $\begin{array}{l}\text { Smaller community } \\
\text { (pop. less than } \\
50,000 \text { ) }\end{array}$ & $2(2)$ & \\
\hline \multicolumn{3}{|c|}{$\begin{array}{l}\text { *Demographic data were provided for the nonresponder col- } \\
\text { umn for comparison with participating program by individ- } \\
\text { ual review of each residency program's information on the } \\
\text { Society for Academic Emergency Medicine database and } \\
\text { their individual program websites. There were data available } \\
\text { for } 41 \text { of } 44 \text { nonresponders. }\end{array}$} \\
\hline
\end{tabular}

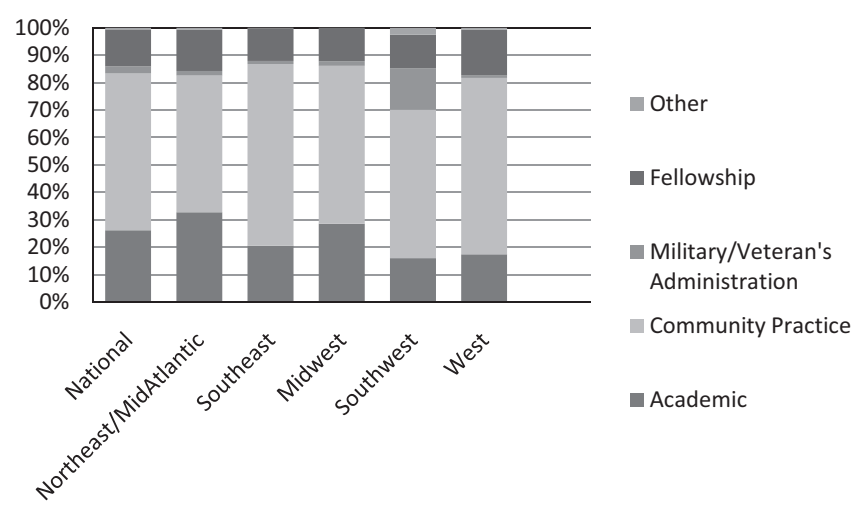

Figure 1. National and regional data.

fellowship equaling 13.5\%, military/Veteran's Administration (VA) 2.6\%, and other choices accounting for $0.6 \%$ (Figure 1).

\section{Regional Differences}

Statistical analysis demonstrated greater academic career choice in programs located in the Northeast/Mid-Atlantic and Midwest regions in comparison to the other regions reviewed (see Table 2, Figure 1). 


\begin{tabular}{|c|c|c|c|}
\hline Model Parameters & Beta & $95 \% \mathrm{Cl}$ for Beta & $\mathrm{p}$-value \\
\hline Intercept & 17.017 & 3.145 to 30.890 & 0.017 \\
\hline $\begin{array}{l}\text { Program } \\
\text { configuration }\end{array}$ & & & \\
\hline $\begin{array}{l}\text { PGY 1-3 } \\
\text { PGY } 2-4 \text { and } \\
\text { PGY } 1-4\end{array}$ & $\begin{array}{c}-1.976 \\
\text { Reference }\end{array}$ & -10.379 to 6.427 & 0.638 \\
\hline Region & & & \\
\hline Northeast & Reference & & \\
\hline Southeast & -12.829 & -24.629 to -1.029 & 0.034 \\
\hline Midwest & -2.874 & -11.962 to 6.213 & 0.527 \\
\hline Southwest & -20.021 & -33.402 to -6.641 & 0.004 \\
\hline West & -10.987 & -24.031 to 2.057 & 0.097 \\
\hline Program size (per & sident class & & \\
\hline Size $<8$ & Reference & & \\
\hline Size 9 to 11 & 2.735 & -7.502 to 12.970 & 0.593 \\
\hline Size $>12$ & 11.882 & 2.895 to 20.870 & 0.011 \\
\hline $\begin{array}{l}\text { Academic } \\
\text { productivity }\end{array}$ & 0.248 & 0.064 to 0.433 & 0.009 \\
\hline $\begin{array}{l}\text { The outcome mo } \\
\text { entering a career } \\
\text { preted as the esti } \\
\text { (Northeast, 4-year } \\
\text { Each parameter es } \\
\text { across categories } \\
\text { from programs in } \\
\text { pared to those fro } \\
\text { gram configuratic } \\
\text { size). } \\
\text { PGY = postgradua }\end{array}$ & $\begin{array}{l}\text { eled was } t \\
\text { academics } \\
\text { ate for a pr } \\
\text { size }<8 \text { ) wit } \\
\text { mate provic } \\
\text { g., approxi } \\
\text { e Southeas } \\
\text { the Northe } \\
\text { academic } \\
\text { year. }\end{array}$ & $\begin{array}{l}\text { he percentage of } \\
\text { The intercept can } \\
\text { gram at all referen } \\
\text { h no academic pro } \\
\text { es a potential for } \\
\text { mately } 20 \% \text { fewer } \\
\text { enter academics wh } \\
\text { ast, while controllins } \\
\text { productivity, and }\end{array}$ & $\begin{array}{l}\text { aduates } \\
\text { ee inter- } \\
\text { e levels } \\
\text { uctivity. } \\
\text { mparing } \\
\text { aduates } \\
\text { en com- } \\
\text { for pro- } \\
\text { orogram }\end{array}$ \\
\hline
\end{tabular}

\section{Program Size}

Program size was examined as an independent predictor of increased academic career selection. The data from the survey demonstrated greater academic choice with larger programs (greater than 12 residents per year) even after other covariables were accounted for in the analysis (Table 1, Figure 2).

\section{Program Setting}

Location of the program within an urban setting was explored as a possible factor in increased academic career selection. Program directors were asked to describe the size of the surrounding population around

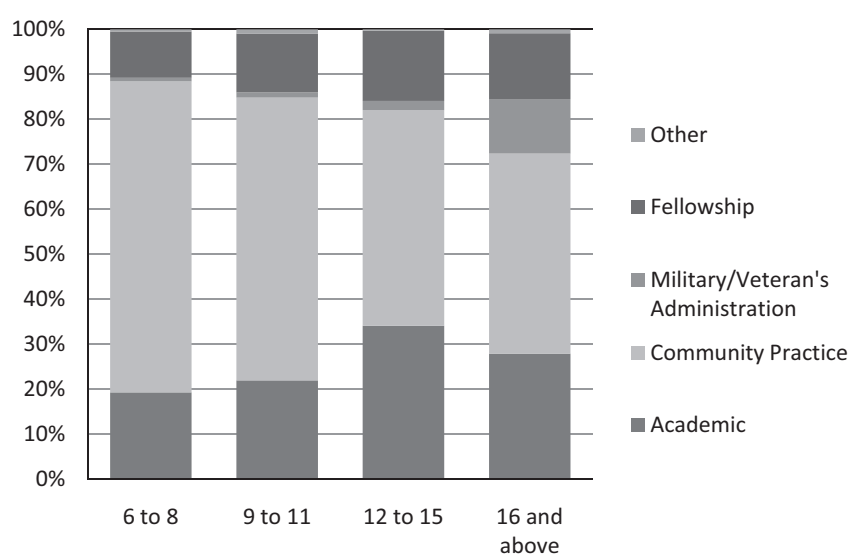

the primary residency site. No differences were found between these groups.

\section{Academic Resident Productivity}

Multiple potential markers of resident research productivity that might correlate with preparation for future academic work were examined using the program director survey. These included percentage of residents creating peer-reviewed publications and nonpeer-reviewed publications and residents presenting original research at meetings. We found statistical significance with non-peer-reviewed publication and meeting presentations, but not for peer-reviewed publications. The two significant predictors (non-peerreviewed publications and presentations) were aggregated to create an academic productivity variable in the linear regression model shown in Table 2.

\section{Program Type}

Previous studies have found significant differences between 3-year programs and 4-year programs with regard to pursuing an academic career. Initial review of our data revealed a trend toward increased academic career choice in 4-year programs. This effect decreased in multivariate analysis and never demonstrated independent statistical significance. Program types PGY 1-4 and PGY 2-4 were combined as there are insufficient numbers of PGY 2-4 programs currently active to likely be statistically significant when compared to the two more common program types, and the additional year of training appeared to make them more compatible with PGY 1-4 programs for analysis (Figure 3).

\section{Program Mentoring and Career Track}

In addition to the variables described above, we solicited information on the presence of formal faculty mentorship programs as well as career track programs within each residency program. A significant difference between programs was not demonstrated within our data when mentoring and career track were examined.

\section{Statistical Model}

Following that analysis, a linear regression was performed and a model was fitted using the stated variables that accounted for approximately $30 \%$ of the variation seen between programs as reported in the

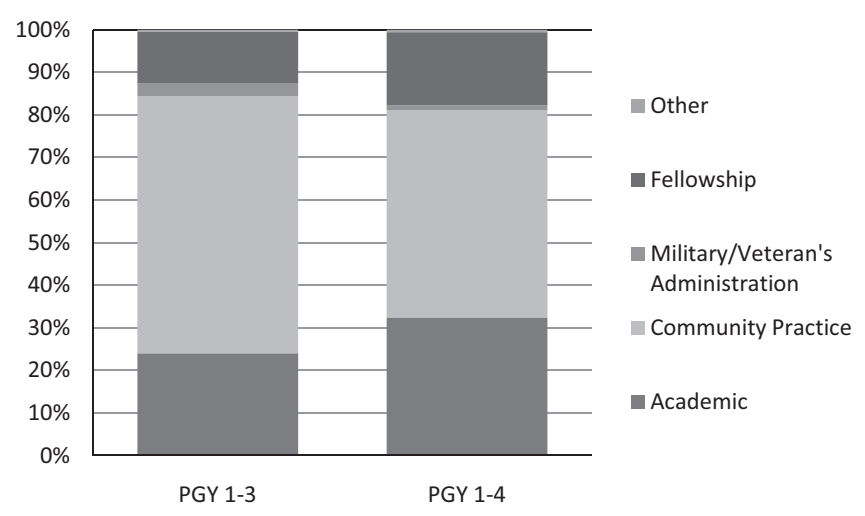

Figure 3. Program type. PGY = postgraduate year. 
survey $\left(R^{2}=0.401\right.$, adjusted $\left.R^{2}=0.295\right)$. Academic productivity, region, and program size were associated with increased entry into academic EM.

\section{DISCUSSION}

Our study met our two major aims: first, it successfully provided a current rate of residents choosing an academic career in EM, and second, it provided new programmatic variables associated with those residencies that were associated with a higher number of graduates entering an academic career. Using similar methods as previous studies, we found a slightly increased proportion of residents selecting an academic career in comparison to the most recent previous work $(23.1 \%){ }^{5}$ However, there was general concordance between the three when taken in average with other pertinent studies $(28.0 \%))^{4,5}$ Accordingly, there does not appear to be a significant trend toward either increasing or decreasing the rate of academic career selection in EM.

With regard to those factors most likely associated with an increased rate of academic career selection, our initial hypothesis was that there would be a significant difference between 3-year programs (PGY 1-3) and 4-year programs (PGY 1-4 and PGY 2-4) favoring increased academic careers in graduates of the 4-year residencies as had previously been demonstrated. ${ }^{4,5}$ In our study, however, this finding was not replicated, which suggests that program size, region, and academic productivity may have driven the previously observed effect. When these factors were accounted for in our multivariable model, the difference between 3- and 4-year programs was further attenuated. In fact, the extremely wide confidence interval (CI) appears to suggest somewhat strongly against such a relationship existing at all, especially after accounting for region of country, program size, and academic productivity. This may represent a need for a change in thinking about which programs are most likely to cultivate new faculty members.

Our analysis showed meaningful differences between programs based on the region of the country they were located in, their program size, and the academic and research productivity of their residents. Success in preparing a scholarly publication has been previously evaluated in radiology residents as a marker of future academic productivity and has been shown to have a weak correlation. ${ }^{13}$ Previous research on the role of mentorship in academic career success had been explored by Ogunyemi et al. ${ }^{14}$ in 2010, in which their program showed an increase in resident research production; however, no significance was found in our study. Program location and size have not previously been used to describe differences in academic career selection, but do provide an alternative explanation for previously seen data. Of note, none of these studies were designed to demonstrate causality. The programmatic factors described in this study can be thought to either describe programs more likely to attract future residents interested in an academic career or to cultivate an interest in academics from undifferentiated residents. The association seen with increased academic production may lean toward supporting the latter explanation; however, this study was not designed to entirely differentiate between these two. Further research at the individual resident level could be helpful in increasing our understanding in this area. Additionally, there exists a possibility of a confounding variable that could explain some of the above differences and those found in previous studies, but which has not yet been described. One such variable may be that programs in the Northeast and Midwest that are of larger size, and perhaps more often are in a 1-4 year format, are associated with institutions with a higher emphasis on academic career choice in other medical specialties. Additionally in the same region, there are a greater number of academic sites in which residents may find a first position in the same geographical area as their residency program.

Additional study of programmatic variables is necessary to both validate these findings and expand them. The development of a prediction rule for academic career selection was not a stated goal of this study. Continued data collection and refinement of this model may provide for creation of a predictive model in the future, but much greater study is required to accomplish this goal. Repeated surveys over time will be helpful in validating these findings, especially as they differ from those of previous studies, as well as in following important trends within the field. This study represents a starting point within the larger context in which medical career selection lies within our profession and society as a whole. Ultimately, further research is warranted into career selection in residency as it represents an important decision point in individual's career choices with larger societal effects.

\section{LIMITATIONS}

The first limitation derives from the nature of the survey design and its participants. All survey data are subject to recall bias. Our data are based on program director memory and individual program internal records and documents not available to authors. However, there is no reason to believe that there is a significant difference in these factors between individual program responses. A second limitation is that this study design is not intended to prove causality, but instead describes correlations between the independent variables and the dependent variable of increased academic career selection. Therefore, while information can be gleaned from the study regarding these correlations, and while clear confounders that would invalidate the correlations have been reviewed, a perfect causeand-effect relationship cannot be proven. An additional set of limitations is an unavoidable byproduct of the response rate to the survey as well as the completeness of answers provided. Our response rate was 103 of 147 total programs, a subset of the responses were incomplete or uninterpretable and thus could not be included in all areas of the analysis. When compared, responding programs and those who did not respond appeared generally demographically similar and there was no obvious bias in the types of programs that submitted incomplete or compromised responses. Additionally, only one PGY 2-4 program provided data, and thus 
they were generally included in the PGY 1-4 group in program type for analysis. Finally, while there were multiple statistically significant findings, there were relatively large CIs associated with some of these findings, which may represent an underpowered study. Unfortunately, there are only a set number of American EM programs available for survey, and despite multiple attempts to maximize survey response, this is a limitation of the reported results.

\section{CONCLUSIONS}

We found that program region, size, and research productivity were the best indicators of academic career selection. Program length was not found to be predictive, and this is a departure from previous studies. While many of these factors are not modifiable, increased resident academic productivity was associated with an increase in the number of graduates choosing an academic career. This suggests that decision-makers interested in this issue may look to cultivate research opportunities for their residents. Further research is necessary to further validate these findings, as well to provide important context to their general applicability for policy-makers and program directors.

The authors thank David Mickey-Pabello, graduate student at the University of Michigan, for assistance in performance of the literature search necessary for manuscript creation.

\section{References}

1. Ginde AA, Sullivan AF, Camargo CA Jr. National study of the emergency physician workforce, 2008. Ann Emerg Med. 2009; 54:349-59.

2. Holliman CJ, Wuerz RC, Hirshberg AJ. Analysis of factors affecting U.S. emergency physician workforce projections. Ann Emerg Med. 1997; 4:731-5.

3. Holliman CJ, Wuerz RC, Chapman DM, et al. Workforce projections for emergency medicine: how many emergency physicians does the United States need? Ann Emerg Med. 1997; 4:725-30.

4. Stern SA, Kim HM, Neacy K, Dronen SC, Mertz M. The impact of environmental factors on emergency medicine resident career choice. Acad Emerg Med. 1999; 6:262-70.

5. Lubavin BV, Langdorf MI, Blasko BJ. The effect of emergency medicine residency format on pursuit of fellowship training and an academic career. Acad Emerg Med. 2004; 11:938-43.

6. Boyd JS, Clyne B, Reinert SE, Zink BJ. Emergency medicine career choice: a profile of factors and influences from the Association of American Medical Colleges (AAMC) graduation questionnaires. Acad Emerg Med. 2009; 16:544-9.

7. Steele MT, Schwab RA, McNamara RM, Watson WA. Emergency medicine resident choice of practice location. Ann Emerg Med. 1998; 31:351-7.

8. Steele MT, Watson WA, Ma OJ. Percentage of emergency medicine residency graduates who got their first choice of jobs did not change between 1995 and 1997. Am J Emerg Med. 2000; 18:152-5.

9. Sanders AB, Fulginiti JV, Witzke DB. Factors influencing resident career choices in emergency medicine. Ann Emerg Med. 1992; 21:47-52.

10. Sanders AB, Fulginiti JV, Witzke DB, Bangs KA. Characteristics influencing career decisions of academic and nonacademic emergency physicians. Ann Emerg Med. 1994; 23:81-7.

11. Katz ED, Katz JT. Careers of graduates of combined emergency medicine/internal medicine programs. Acad Emerg Med. 2002; 9:1457-9.

12. Balboni TA, Chen MH, Harris JR, Recht A, Stevenson MA, D'Amico AV. Academic career selection and retention in radiation oncology: the Joint Center for Radiation Therapy experience. Int J Radiat Oncol Biol Phys. 2007; 68:183-6.

13. Patterson SK, Fitzgerald JT, Boyse TD, Cohan RH. Is past academic productivity predictive of radiology resident academic productivity? Acad Radiol. 2002; 9:211-6.

14. Ogunyemi D, Solnik MJ, Alexander C, Fong A, Azziz R. Promoting residents' professional development and academic productivity using a structured faculty mentoring program. Teach Learn Med. 2010; 22:93-6. 